\title{
KNOWLEDGE, ATTITUDE, AND PRACTICE ON DOPING OF MALAYSIAN STUDENT ATHLETES
}

\author{
LIM MING CHIANG ${ }^{1}$, AHMAD FUAD SHAMSUDDIN², TUAN MAZLELAA TUAN MAHMOOD ${ }^{1 *}$
}

${ }^{1}$ Quality Use of Medicines, Faculty of Pharmacy, Universiti Kebangsaan Malaysia, Jalan Raja Muda Abdul Aziz - 50300 Kuala Lumpur, Malaysia. ${ }^{2}$ Department of Pharmacy, Faculty of Pharmacy and Health Sciences, Universiti Kuala Lumpur Royal College of Medicine Perak, Jalan Greentown - 30450, Ipoh, Perak, Malaysia. Email: tuanmazlelaa@ukm.edu.my

Received: 10 November 2017, Revised and Accepted: 16 January 2018

\section{ABSTRACT}

Objective: The aim of the study is to measure the knowledge, attitude, and practice of drugs use in sports among Malaysian student athletes.

Methods: This was a cross-sectional, self-administered survey of student athletes studying in six universities and two sports schools in Malaysia. Athletes were approached at their schools or universities and were explained about the study. If they agreed to participate, they were asked to provide written informed consent and fill in the survey. Participation in the study was voluntary and no incentives were given.

Results: Overall, 182 respondents were recruited for this study. Most of the respondents were male, age between 16 and 18 years old and had participated in international sports competition. The knowledge of the respondents on drugs in sports was found to be moderate with the median score of 11 per 18. The overall mean performance enhancement attitude scale scores, a measure of doping attitudes, for all respondents were $44.63 \pm 13.03$ indicating they are having a negative attitude toward doping. Meanwhile, $12 \%$ of the respondents had been offered doping agents by any parties with $13.7 \%$ of them are using it for medical purpose while $4.4 \%$ of them had used it for other purposes.

Conclusion: Young athletes should be better equipped with knowledge on the dangers of doping and have a firm stance against doping. Thus, specific educational package and special courses should be provided to address the knowledge gap observed among the athletes in this study apart from enhancing their attitude toward the importance of anti-doping.

Keywords: Doping, Student athletes, Drugs in sports.

(C) 2018 The Authors. Published by Innovare Academic Sciences Pvt Ltd. This is an open access article under the CC BY license (http://creativecommons. org/licenses/by/4. 0/) DOI: http://dx.doi.org/10.22159/ajpcr.2018.v11i5.23598

\section{INTRODUCTION}

The misuse of drugs in sport is not something new in the sports world. Various medications were already been used to enhance the performance of athletes since the $3^{\text {rd }}$ century BC [1]. Nowadays, doping has evolved into a more systematic doping pattern that involves the entire team. Recently in 2016, a state-sponsored doping program involving the Russian teams had banned up to 118 athletes from participating in the 2016 Rio Olympic Games [2]. In Malaysia, there were numbers of doping cases reported among young budding athletes. Up to four medalists were tested positive for doping at the 2016 Malaysian Games catered for budding athletes under 21 years old. Two of them were archers who took sibutramine while two others were a weightlifter taking anabolic-androgenic steroid (AAS) and a boxer with traces of diuretics [3].

Athletes, as they progress in their sports career, are gradually having the constant desire to improve and win. Thus, it is possible that young athletes may turn to doping agents even before reaching their best career years as the prevalence of doping, especially the use of AAS, is well documented among adolescents [4]. The improper use of drugs including the use of lifestyle drugs for muscle building and weight loss in sport actually represents a true health risk to the users and at the same time risk cutting their career short [5]. Apart from intentional doping, inadvertent doping may occur if the athletes practice selfmedication without consulting the healthcare professionals. This is particularly common among athletes with medical knowledge [6]

The use of doping agents among athletes sends an unacceptable message about culture of drugs use in sports. Some experts claimed that increasing the public prosecution of the offenders in doping cases and doing more drug testing might deter the athletes from doping [7]. However, a better approach that targets the root of problem using proper education as primary prevention of doping should be considered [8]. Thus, to develop an appropriate educational package for the young athletes, it is important to first identify the athletes' knowledge and attitude toward doping. This is because attitudes can be considered as an index of doping behavior and a greater leniency toward doping could be linked to the use of prohibited substances [9]. A better understanding of athletes' knowledge, attitude, and practice in the use of drugs in sports could help to formulate a better anti-doping program.

Many studies had been done overseas focusing on young athletes to better understand their knowledge and attitude toward doping. The knowledge of West-Austrian junior athletes on doping was reported in 2013 [8]. Besides, Nolte and colleagues [10] had reported on knowledge and attitude of African high school athletes on doping. Other similar studies were conducted in Uganda and Korea to learn about the doping issue among young athletes [11,12]. Most of the researchers reported that young athletes have a moderate level of knowledge on doping and some will consider using performance-enhancing substances if they knew they would not get caught.

With the continuous development of Malaysian sports environment and achievements in international events, more athletes can be susceptible to doping. Nevertheless, information about doping awareness among athletes in Malaysia is scarce. Thus, in this research, we shall highlight the doping knowledge, attitude, and practice of Malaysian student athletes.

\section{METHODS}

This was a cross-sectional study on the knowledge, attitude, and practice of Malaysian student athletes toward doping conducted 
through self-administered questionnaires over a period of 5 months from February to June 2017. Ethical approval for this study was sought from The National University of Malaysia Research Ethics Committee (UKM PPI/111/8/JEP-2017-010).

Student athletes from two sports schools and six selected universities were invited to participate in the study. These academic institutions were chosen due to their active participation in national and international sports events. Thus, the respondents recruited shall reflect the actual elite sports society. The inclusion criteria of the respondents include secondary school student athletes studying in sports schools in 2017 of age 13 years old and above and university student athletes studying in university in 2017 who had participated in the past National University Games. Surveys with completion of $<80 \%$ were excluded from the study.

There were 1498 student athletes from the selected educational institutions. Hence, a sample size of 306 respondents was required using the sample size calculation by Krejcie and Morgan [13]. By taking the ratio of secondary school athletes to university athletes, the numbers needed are 156 and 150, respectively. Athletes were approached at their schools or universities. They were explained about the study and if they agreed to participate, they were asked to provide written informed consent and fill in the survey. Participation in the study was voluntary and no incentives were given.

The questionnaire for this study was adapted from previous literature in the area. The survey comprises four sections. Section A is about the sociodemographic backgrounds of the respondents [14] and section B is about their knowledge on doping [8]. Assessment of the knowledge is done based on the marks that the respondents obtain. Each correct answer will be awarded one mark while a wrong answer or answering "Don't know" will be given zero mark. The respondent's score is graded as good if score $\geq 85 \%$, moderate if score $61-84 \%$, and poor if $\leq 60 \%$ [15]. In section $\mathrm{C}$, respondents were asked about their attitude on doping using the performance enhancement attitude scale (PEAS) which has been validated (Cronbach's alpha: 0.71-0.91). It is in the form of Likert scale where it ranges from negative response to positive response [16]. In the last section, section $\mathrm{D}$, respondents were asked about practice and experience in drugs and supplements use in sports. This section consists of five yes-no questions and three multiple choice questions [17].

A pilot study to evaluate the content validity and reliability of the study was carried out on 10 university and sport school students and two academicians who are expert in the area. Following the feedback from the respondents, the questionnaire was further improved. The reliability test calculated on section $\mathrm{C}$ using Cronbach's alpha shows a result of 0.77

Data were analyzed using SPSS software version 23. All categorical demographic data were presented in frequency and percentage. The level of statistical significance for all inferential tests was set at $\mathrm{p}<0.05$. In the analysis of the relationship between students' knowledge score with demographic data, Kruskal-Wallis test was used for the level of participation and achievement while Mann-Whitney U-test was employed to look for association with gender. For the analysis of the relationship between students' PEAS score with demographic data and knowledge, one-way ANOVA was used for the categorical variables more than two groups (race, educational level) while independent t-test was employed to look for association with gender. Finally, to evaluate the relationship between students' practice on doping with demographic data, knowledge, and attitude, Chi-square test was used for categorical data (gender, knowledge grade) while ANOVA was used for the relationship between experience in doping with the PEAS score.

\section{RESULTS}

A total of 379 surveys were distributed and of these, 186 were returned. However, four respondents were removed from the study due to failure to complete $>80 \%$ of the survey form, leaving 182 responses to be analyzed.
The majority of the respondents are male (59.9\%), between the age of 16 and 18 years old, involved in sports very actively with training hours more than 15 hours per week (43.4\%), Malays (57.7\%), have participated in international competitions (42.9\%) and have achievement in at least national competition (67.6\%). The top three types of sports that the respondents represented are track and field, football and martial arts which account for $51.6 \%$ of total respondents. The least number of respondents come from fencing, handball, hockey, rowing, and softball which accounts for only $0.5 \%$ each. The summary of respondents demographic and characteristic is presented in Table 1.

Based on the analysis, the median score for total respondents in this study was 11 per 18 with interquartile range of 3 . Respondents were found to have a moderate knowledge related to drugs in sports. The responses were summarized in Table 2 . The level of participation and the level of achievement in sports were reported to have a significant difference with the knowledge score $\left({ }^{*} \mathrm{p}<0.01 ;{ }^{* *} \mathrm{p}<0.01\right)$. However, there was no significant level of difference between their knowledge with gender $\left({ }^{*} \mathrm{p}=0.404\right)$.

From the survey, the mean score for the PEAS of total respondents that participated in this study was $44.63 \pm 13.03$. Respondents were found to have a negative attitude toward drugs use in sports. Besides, there was a significant difference between the attitude with gender and race, respectively $\left({ }^{*} \mathrm{p}<0.01 ;{ }^{* *} \mathrm{p}=0.041\right)$. However, there was no significant level of difference between their attitudes with educational level $\left({ }^{*} p>0.05\right)$. The responses were summarized in Table 3.

Results showed that only 22 respondents (12.1\%) had ever being offered doping agents. A total of 33 respondents (12\%) had personal experience with doping agents or methods regardless they use it for medical purposes $(n=25 ; 13.7 \%)$ or other purposes $(n=8 ; 4.4 \%)$.

Table 1: Sociodemographic characteristics of the respondents $(n=182)$

\begin{tabular}{ll}
\hline Characteristics & $\mathbf{n}(\%)$ \\
\hline Age & $17 \pm 5^{\mathrm{a}}$ \\
$16-18$ & $109(59.9)$ \\
$19-21$ & $23(12.6)$ \\
$22-24$ & $42(23.1)$ \\
Above 25 years old & $8(4.4)$ \\
Gender & \\
Male & $109(59.9)$ \\
Female & $73(40.1)$ \\
Race & \\
Malay & $105(57.7)$ \\
Chinese & $60(33.0)$ \\
Indian & $13(7.1)$ \\
Others & $4(2.2)$ \\
Highest education level & \\
Form 4 & $31(17.0)$ \\
Form 5 & $77(42.3)$ \\
Form 6 & $11(6.0)$ \\
Bachelor's Degree & $62(34.1)$ \\
Master's Degree & $1(0.5)$ \\
Duration of training (per week) & \\
s10 h & $51(28.0)$ \\
11-15 h & $52(28.6)$ \\
>15 h & $79(43.4)$ \\
Level of participation & \\
State & $18(9.9)$ \\
University & $31(17.0)$ \\
National & $55(30.2)$ \\
International & $78(42.9)$ \\
Level of achievement & \\
State & $26(14.3)$ \\
University & $33(18.1)$ \\
National & $60(33.0)$ \\
International & $63(34.6)$ \\
\hline a - Median+Interquartile range &
\end{tabular}


Table 2: The respondents' knowledge toward drugs use in sports $(n=182)$

\begin{tabular}{|c|c|c|c|}
\hline Domains & Variables & $\begin{array}{l}\text { Number of } \\
\text { respondents with } \\
\text { correct answer, } n(\%)\end{array}$ & $\begin{array}{l}\text { Number of respondents } \\
\text { with wrong answer/not sure } \\
\text { answer, } \mathbf{n}(\%)\end{array}$ \\
\hline \multirow{10}{*}{$\begin{array}{l}\text { Knowledge on prohibited } \\
\text { substances in sports }\end{array}$} & Which of the following substance (s) & & \\
\hline & is/are listed on the World Anti-Doping & & \\
\hline & Agency prohibited list? & & \\
\hline & (i) AASs & $159(87.4)$ & $23(12.6)$ \\
\hline & (ii) Stimulants (Cocaine) & $118(64.8)$ & $64(35.2)$ \\
\hline & (iv) Caffeine (Coffee) & $134(73.6)$ & $48(26.4)$ \\
\hline & (v) Protein & $177(97.3)$ & $5(2.7)$ \\
\hline & (vi) Panadol & $166(91.2)$ & $16(8.8)$ \\
\hline & (vii) Cigarette & $144(79.1)$ & $38(20.9)$ \\
\hline & (viii) Alcohol & $58(31.9)$ & $124(68.1)$ \\
\hline \multirow[t]{4}{*}{$\begin{array}{l}\text { Knowledge on definition } \\
\text { of doping }\end{array}$} & $\begin{array}{l}\text { Doping involves inadvertent use of } \\
\text { prohibited substances by athletes }\end{array}$ & 85 (46.7) & $97(53.3)$ \\
\hline & $\begin{array}{l}\text { Doping involves presence of prohibited } \\
\text { substances under prohibited list in } \\
\text { athlete's urine sample }\end{array}$ & $143(78.6)$ & $39(21.4)$ \\
\hline & $\begin{array}{l}\text { Doping involves tampering with doping } \\
\text { sample collection }\end{array}$ & $52(28.6)$ & $130(71.4)$ \\
\hline & $\begin{array}{l}\text { Doping involves refusing to undergo } \\
\text { doping sample collection }\end{array}$ & $63(34.6)$ & $119(65.4)$ \\
\hline $\begin{array}{l}\text { Knowledge on national } \\
\text { anti-doping agency }\end{array}$ & $\begin{array}{l}\text { What is the abbreviation "Adamas" stands } \\
\text { for? }\end{array}$ & $12(6.6)$ & $170(93.4)$ \\
\hline
\end{tabular}

AAS: Anabolic-androgenic steroid

Table 3: The respondents' attitude in drugs use in sports $(n=182)$

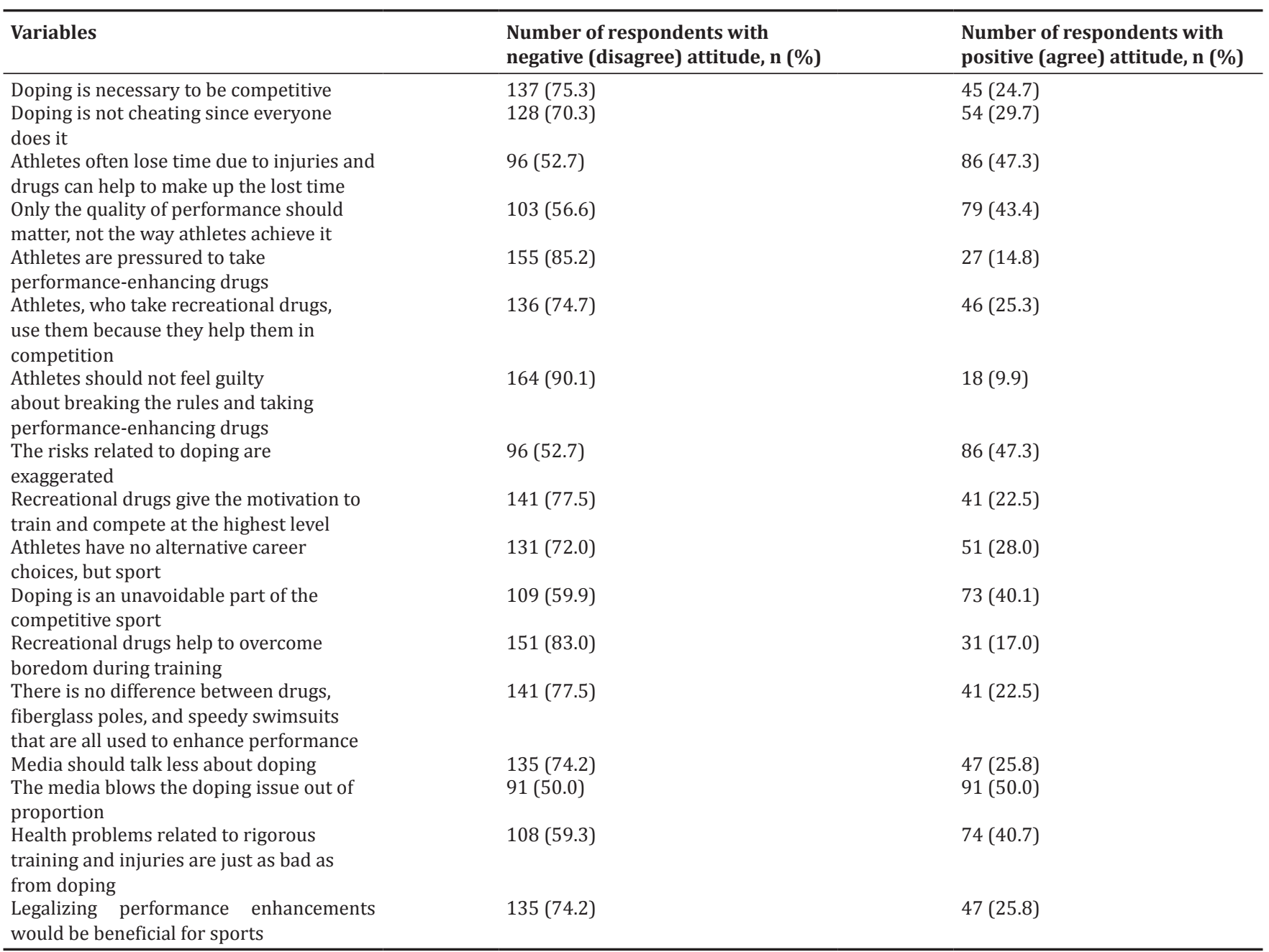


However, up to $20.9 \%$ of the respondents are sure that there are some other athletes in their sports community who have used doping. Besides, about half of the respondents do take supplements and they usually get the supplements from coach. The most important source of information for taking supplements that the respondents will refer to will be coach $(25.8 \%)$, followed by team physician $(24.7 \%)$, nutritionist (16.5\%), pharmacist (15.4\%), and family members (7.1\%)

The relationship between demographic data and the knowledge grade with the practice of respondents was analyzed and found significant difference between the gender, knowledge grade, level of participation, and achievement in sports with personal experience in doping $\left({ }^{*} \mathrm{p}<0.01\right)$

\section{DISCUSSION}

The current study found that participants that took part in national level sports events were having a higher knowledge score than both state and international level. This is in contrast with the study that reported that Kenyan elite athletes with more experience in higher levels of competition had a better knowledge since they are better exposed to officials or anti-doping officers [18].

Regarding the definition of doping in the World Anti-Doping Code, it is found that generally, the respondents did not understand it well. Most of the respondents know that doping involves the presence of prohibited substances in urine sample, but only a few of them know that doping involves refusing to undergo doping sample collection. These findings are consistent with the study done previously [11]. Thus, it is important to educate the athletes on the definition of doping to prevent athletes from violating the rules unintentionally.

Besides, this study shows that more than $85 \%$ of the respondents had correctly identified AAS as doping agent while around $60 \%$ of them had correctly identified stimulants as doping agents. It is encouraging to compare this figure with that found by Fürhapter et al. reported that approximately $85 \%$ of the junior athletes are able to identify AAS as doping agent while about $75 \%$ of them know that stimulants are prohibited [8]. This is most probably because AAS and stimulants are the most commonly abused substances in sports reported by WADA [19]. Thus, the respondents had better exposure to news or information on these substances. Besides, more than $90 \%$ of the respondents were unaware of the official anti-doping agency in Malaysia being AntiDoping Agency of Malaysia (Adamas). This is most probably due to lower awareness of the respondents on the doping issue.

In short, this recent study had shown that generally the respondents had a moderate level of knowledge regarding doping. This was similar to the previous findings when the majority of the German athletes were found to have poor to moderate knowledge [20]. These findings pointed out the need to improve the limited knowledge of athletes by establishing more educational course on drugs in sport.

Male respondents were found to have a higher mean PEAS score indicating that they have a more permissive attitude to the use of doping agents [21]. Normally, higher achievement in sport would place the athletes at higher pressure and desire to win, thus making doping more acceptable for them. However, in our study, there was no significant difference between the PEAS scores with respect to the level of participation or achievement in sports.

Apart from that, the findings had shown that majority of the respondents disagreed that doping is necessary to be competitive. This finding corroborates the study of Petroczi that $80 \%$ of the respondents believed that winning without doping is possible even at high level [22]. Besides, only $25 \%$ of the respondents agreed to legalize performance enhancements in sport. Almost all of the respondents also felt that athletes should feel guilty about breaking the rules and taking performance-enhancing drugs. Thus, from these studies, we can see that respondents are unwilling to follow the doping culture and generally against this practice of doping in sport. Authorities and regional anti-doping agency shall continue to embed the culture of antidoping with strict penalty and firm stance against those who involved in doping.

From the results, it was shown that $12 \%$ of the respondents had been offered doping agents or methods before in their sports career. This is comparable to the study done by Fürhapter et al. [8]. Besides that, similar studies during 2006 and 2015 had reported that $15 \%$ and $9.3 \%$ of the athletes had been offered banned substances, respectively [21,11].

Nevertheless, only $4.4 \%$ of the respondents were found to have a personal experience with prohibited substances. This finding accords with the earlier report on Korean athletes [12]. Moreover, when asked whether they personally knew any other athletes in their sports community that doped, up to $21 \%$ were sure that there are someone who have been doping while another $32 \%$ believe that some athletes might involve in doping but not sure about their guess. This is in line with the study by Muwonge et al. [11]. A possible explanation for these results may be due to the news reports on athletes from the same sports society being caught doping either nationally or internationally.

This study had revealed that respondents who had personal experience in doping had a higher mean PEAS score compared to those without such experience. It was presumed that the athletes that admitted using doping substances were more likely to think that others were using them too. This was in line with the study by Kim and Kim [12].

Besides, about half of the respondents in this study have experience in using dietary supplements. Although not majority of the respondents took supplements, it is still important to ensure all the respondents that use supplements know the appropriate place to get their supplements and the exact content in their supplements to prevent inadvertent intake of prohibited substances.

For the choice of the most important source of information for taking supplements, coach was top in the list. This was in line with other studies which found that the most frequently referred source of information is the coach $[10,11,20]$. Although the athletes consider coach as the most reliable source of information, they are not professionally trained in this sector. Healthcare professionals shall play a more important role in providing information to the athletes. Although the use of supplements seems to be safe and it is a common practice for athletes to take supplements. However, supplements especially those bought from unreliable online source might be contaminated or purposely added with performance-enhancing agents to boost the sales. In 2001, from 634 supplements analyzed for prohormones, 94 were found to contain hormones or prohormones [23]. Thus, it is essential for all the athletes to refer to the appropriate source of information before trying any supplements to avoid unwanted incidents to occur.

This present study has few limitations. First, the response rate to the questionnaire was lower than the targeted numbers which might influence the accuracy of the results. Besides, the study was done in six universities and two sports schools only and might not represent the overall population. Thus, the results obtained in this study may not be generalized. In addition, research work based on self-reporting questionnaire covering the experience and practice on doping has limitation that the respondents may not wish to reveal that they or their teammates use drugs, even if anonymity and confidentiality are guaranteed.

\section{CONCLUSION}

The knowledge of the student athletes was generally found to be moderate and they have refusal attitude toward doping. The confessed use of doping agents in this study was low. Despite that, effort must be done to improve athletes' knowledge to empower them to make a better decision when confronted with doping situation. The results of the study at hand are comparable to those of previous studies in other 
countries. This result can be useful in formulating a more focused and complete anti-doping awareness interventions to help in controlling the doping incidents in Malaysia. Besides, the lack of appropriate knowledge on drugs use in sports maybe partially caused by the inadequate sport education curriculum. Thus, this report shall support the continuation of efficient and effective anti-doping strategies to protect the athletes' health from inappropriate use of drugs in sport apart from keeping the ethics and moral within sports.

\section{ACKNOWLEDGMENTS}

We are grateful to Educational Planning and Research Division of Ministry of Education Malaysia, Sports Division of Ministry of Education Malaysia, and Educational Planning and Research Division of Ministry of Higher Education Malaysia, for approving and supporting our study.

\section{AUTHOR CONTRIBUTIONS}

Lim Ming Chiang: Constructing an idea or hypothesis for research and/ or manuscript; planning methodology to reach the conclusion; taking responsibility in execution of the study, data management and reporting; taking responsibility in logical interpretation and presentation of the results; taking responsibility in the construction of the manuscript. Ahmad Fuad Shamsuddin: Critically reviewing the article for its intellectual content, acquisition of data, analysis and interpretation of data; ensuring a proper explanation to possible questions that could be raised regarding accuracy and scientific integrity of the submitted manuscript Tuan Mazlelaa Tuan Mahmood: Organising and supervising the course of the project or the article and taking the responsibility; critically reviewing the article for its intellectual content, acquisition of data, analysis and interpretation of data; ensuring a proper explanation to possible questions that could be raised regarding accuracy and scientific integrity of the submitted manuscript.

\section{CONFLICT OF INTEREST STATEMENT}

The authors whose names are listed above certify that they have no involvement in any organization or entity with any financial interest or non-financial interest in the subject matter or materials discussed in this manuscript.

\section{REFERENCES}

1. Müller RK. History of doping and doping control. In: Thieme D, Hemmersbach P, editors. Doping in Sport. Heildelberg: Springer; 2010. p. 1-18.

2. Roan D. Russia and Rio 2016: How the IOC is working up an Olympic compromise. BBC. Available from: http://www.bbc.com/sport/ olympics/36422629. [Last accessed on 2017 Jun 24].

3. Bernama. Come Forward on Sukma Doping, Sport Associations Told. New Straits Times; 2016. Available from: https:/www.nst. com.my/news/2016/10/178066/come-forward-sukma-doping-sportassociations-told. [Last accessed on 2017 Jun 24].

4. Calfee R, Fadale P. Popular ergogenic drugs and supplements in young athletes. Pediatrics 2006;117:e577-89.
5. Reddy P, Gosavi D, Reddy S. Lifestyle drugs. Int J Pharm Pharm Sci 2012;4:43-5.

6. Johnson D, Sekhar HS, Alex T, Kumaraswamy M, Chopra RS. Selfmedication practice among medical, pharmacy and nursing students. Int J Pharm Pharm Sci 2016;8:443-7

7. Butch AW, Lombardo JA, Bowers LD, Chu J, Cowan DA. The quest for clean competition in sports: Are the testers catching the dopers? Clin Chem 2011;57:943-7.

8. Fürhapter C, Blank C, Leichtfried V, Mair-Raggautz M, Müller D, Schobersberger W. Evaluation of West-Austrian junior athletes' knowledge regarding doping in sports. Wien Klin Wochenschr 2013;125:41-9.

9. Sánchez MJ, Zabala M. Doping in sport: A review of elite atheles' attitudes, beliefs and knowledge. Sports Med 2013;43:395-411.

10. Nolte K, Steyn BJ, Kriiger PE, Fletcher L. Doping in sport: Attitudes, beliefs and knowledge of competitive high-school athletes in Gauteng province. SA J Sports Med 2014;26:81-6.

11. Muwonge H, Zavuga R, Kabenge PA. Doping knowledge, attitudes, and practices of ugandan athletes': A cross-sectional study. Subst Abuse Treat Prev Policy 2015;10:37.

12. Kim T, Kim YH. Korean national athletes' knowledge, practices, and attitudes of doping: A cross-sectional study. Subst Abuse Treat Prev Policy 2017;12:7.

13. Krejcie RV, Morgan DW. Determining sample size for research activities. Educ Psychol Meas 1970;30:607-10.

14. Peretti-Watel P, Guagliardo V, Verger P, Mignon P, Pruvost J, Obadia Y. Attitudes toward doping and recreational drug use among french elite student-athletes. Soc Sport J 2004;21:1-17.

15. Wanjek B, Rosendahl J, Strauss B, Gabriel HH. Doping, drugs and drug abuse among adolescents in the state of Thuringia (Germany): Prevalence, knowledge and attitudes. Int J Sports Med 2007;28:346-53.

16. Petróczi A. Attitudes and doping: A structural equation analysis of the relationship between athletes' attitudes, sport orientation and doping behaviour. Subst Abuse Treat Prev Policy 2007;2:34

17. National Collegiate Athletic Association (NCAA). NCAA Study of Substance Use Habits of College Student-Athletes; 2006. Available from: https://www.ncaa.org/sites/default/files/14.\%20Substance $\% 20$ Use\%20Report\%202005.pdf.

18. Chebet S. Evaluation of Knowledge, Attitudes and Practice of Doping Among Elite Middle and Long Distance Runners in Kenya. [Thesis Dr. Phil] School of Applied Human Sciences, Kenyatta University; 2014.

19. Docherty JR. Pharmacology of stimulants prohibited by the world antidoping agency (WADA). Br J Pharmacol 2008;154:606-22.

20. Peters C, Schulz T, Oberhoffer R, Michna H. Doping and doping prevention: Knowledge, attitudes and expectations of athletes and coaches. Dtsch Z Sportmed 2009;60:73-9.

21. Alaranta A, Alaranta H, Holmila J, Palmu P, Pietilä K, Helenius I, et al. Self-reported attitudes of elite athletes towards doping: Differences between Type of sport. Int J Sports Med 2006;27:842-6.

22. Petróczi A, Mazanov J, Naughton DP. Inside athletes' minds: Preliminary results from a pilot study on mental representation of doping and potential implications for anti-doping. Subst Abuse Treat Prev Policy 2011;6:10.

23. Geyer H, Parr MK, Mareck U, Reinhart U, Schrader Y, Schänzer W, et al. Analysis of non-hormonal nutritional supplements for anabolicandrogenic steroids - results of an international study. Int J Sports Med 2004;25:124-9. 